\title{
Estimativa da Evapotranspiração na Mesorregião do Baixo São Francisco
}

\author{
Tatiana Vanessa dos Santos $^{1}$ (D), Ricardo Ferreira Carlos de Amorim ${ }^{1}$ (D), \\ Humberto Alves Barbosa ${ }^{1}$ (D), Fabrício Daniel dos Santos Silva ${ }^{1}$ \\ ${ }^{1}$ Programa de Pós Graduação em Meteorologia, Instituto de Ciências Atmosféricas, \\ Universidade Federal de Alagoas, Maceió, AL, Brasil.
}

Recebido em: 2 de Julho de 2020 - Aceito em: 3 de Dezembro de 2020

\begin{abstract}
Resumo
Um dos fatores mais importantes em qualquer programa de gerenciamento dos recursos hídricos é ter o conhecimento sobre os processos naturais que regulam o ciclo hidrológico. O objetivo desse estudo foi realizar a estimativa da Evapotranspiração de referência (ETo) na bacia hidrográfica do Baixo São Francisco (BSF), com uso do método de PenmanMonteith (PM) recomendado pela Food and Agriculture Organization (FAO), no período de 2009 a 2018. O primeiro passo da pesquisa foi realizar o preenchimento de falhas em dados de superfície, utilizando o método estatístico média preditiva (Predictive Mean Matching-PMM). Após validação desse método, pôde-se estimar a ETo pelo método PMFAO, onde observou-se que a dinâmica temporal da ETo na maior parte das localidades de estudo segue um padrão semelhante, tendo apenas valores diferentes nos seus máximos e mínimos. Com relação aos valores médios diários de ETo, Pão de Açúcar, em Alagoas, teve o maior valor na região de estudo, 4,69 mm.dia ${ }^{-1}$ e Arapiraca, também em Alagoas, o menor valor com 4,18 mm.dia ${ }^{-1}$. A média do total anual acumulado de ETo do BSF para o período foi de $1635,23 \mathrm{~mm} \cdot \mathrm{ano}^{-1}$. A baixa ETo observada durante o período chuvoso (abril a julho) está associada às temperaturas mais baixas. O trabalho obteve bons resultados, se comparado com outros estudos já realizados no BSF.
\end{abstract}

Palavras-chave: variáveis meteorológicas, preenchimento de falhas, recursos hídricos, bacia hidrográfica, evapotranspiração de referência.

\section{Estimation of Evapotranspiration in the Mesoregion of the Lower São Francisco}

\begin{abstract}
One of the most important factors in any water resource management program is having the knowledge about the natural processes that regulate the hydrological cycle. The aim of this study was to estimate the reference Evapotranspiration (ETo) in the Baixo São Francisco watershed (BSF), using the Penman-Monteith (PM) method recommended by the Food and Agriculture Organization (FAO), in the period 2009 to 2018. The first step of the research was to fill in gaps in surface data, using the statistical predictive mean method (Predictive Mean Matching-PMM). After validation of the method, it was possible to estimate ETo using the PM-FAO method, where it was found that the temporal dynamics of ETo in most study locations follow a similar pattern, having only different values in their maximums and minimums. Regarding the average daily ETo values, Pão de Açúcar, in Alagoas, had the highest value in the study region, $4.69 \mathrm{~mm}$. day $^{-1}$ and Arapiraca, also in Alagoas, the lowest value with $4.18 \mathrm{~mm}$.day ${ }^{-1}$. The average of the accumulated annual total of ETo of the BSF for the period was 1635.23 mm.year ${ }^{-1}$. The low ETo observed during the rainy season (April to July) is associated with lower temperatures. The work obtained good results, if compared with other studies already conducted in lower San Francisco.
\end{abstract}

Keywords: meteorological variables, fault filling, water resources, watershed, reference evapotranspiration.

\section{Introdução}

A população de mais de 30 países de regiões áridas e semiáridas deverão sofrer por conta da escassez severa por volta de 2025, significando uma disponibilidade anual de apenas $1000 \mathrm{~m}^{3}$ per capita, com sérias ameaças ao abastecimento humano e agravamento da pobreza rural (Smith,

Autor de correspondência: Tatiana Vanessa dos Santos, tatinessasantos@gmail.com 
2000). A combinação de dois processos separados pelos quais a água é perdida por um lado, da superfície do solo por evaporação e por outro lado, da cultura pela transpiração, é referido como evapotranspiração (ET) (Allen et al., 1998).

O polígono das secas, que de acordo com Marengo (2008) ocupa $62 \%$ da área do Nordeste Brasileiro (NEB), apresenta altos índices de evapotranspiração que acentua os déficits hídricos durante o período de ausência de chuva, bem como tem altas taxas evaporativas em função da intensidade da radiação solar, temperaturas altas, provocando processos de desertificação e ocasionando prejuízos econômicos (Marengo et al., 2016).

A Organização das Nações Unidas para Alimentação e Agricultura (Food and Agriculture Organization - FAO), apresenta no seu Boletim n. 56 o conceito de Evapotranspiração de referência (ETo) como demanda evaporativa da atmosfera, independentemente do tipo de cultura, seu desenvolvimento e práticas de gerenciamento. A FAO estabeleceu no ano de 1990 o método de Penman-Monteith (PM), como o de melhor performance na estimativa padrão da ETo, segundo Smith (1991). Recomendado para determinar a ETo, o método é fisicamente baseado em parâmetros fisiológicos e aerodinâmicos. (Allen et al., 1998).

Diversos trabalhos no Brasil e em outros países confirmam que o desempenho desse método é satisfatório, quando comparado com medidas em lisímetros (Jensen et al. 1990, Allen et al. 1994, Camargo e Sentelhas, 1997, Pereira 1998, Santiago 2001, Medeiros, 2002). Porém, isso não significa que seja operacionalmente perfeito, mas que é baseado em princípios físicos corretos (Cabral, 2014 apud Sediyama, 1996). Segundo Chin e Zhao (1995), há consenso entre os hidrologistas que o método PM-FAO fornece a melhor descrição dos processos, tanto da evaporação quanto da evapotranspiração, sendo que as pesquisas sobre o modelo são divididas em três frentes principais. A primeira e mais difundida é o uso da equação PM-FAO para avaliação e calibração de equações empíricas; a segunda forma de uso da equação padrão é a avaliação e melhoria do seu desempenho em diversas condições climáticas; a terceira vertente de estudos sobre essa equação padrão revela o seu crescente uso em modelos matemáticos hidrológicos e hidráulicos (Silva, 2015 apud Fernandes et al., 2007).

Dentro desse contexto, estudos que estimem a taxa de evapotranspiração em bacias hidrográficas, onde as mesmas exercem influência sobre os processos hidrológicos, como a dinâmica da umidade do solo, recarga de água subterrânea e escoamento superficial são de grande relevância nos estudos hidrológicos regionais (Silva, 2017 apud Liang et al., 2009).

Segundo a ANA (2015), o Baixo São Francisco (BSF) é caracterizado por apresentar períodos críticos de prolongadas estiagens, resultado de baixa pluviosidade e alta evapotranspiração. O BSF integra grande parte de sua área na zona semiárida, fazendo com que o Rio São Francisco desempenhe um importante papel na região que contém uma população de quase um milhão e meio de habitantes. Vale a pena destacar que, a Usina de Xingó localizada no BSF, em termos de potencial hidrelétrico outorgado (3.162 MW), representa atualmente uma das bases de suprimento de energia da região nordeste. Neste cenário, as pesquisas publicadas sobre evapotranspiração nessa região ainda são poucas, havendo poucas estações meteorológicas no seu entorno, o que reforça a importância de mais estudos voltados para o gerenciamento dos recursos hídricos integrantes dessa região, tão marcada pela seca e desigualdades sociais. Sendo assim, o presente trabalho teve o objetivo de estimar a ETo no BSF, com uso de modelo PM-FAO, durante período de 2009 a 2018.

\section{Materiais e Métodos}

\section{1. Área de estudo e obtenção dos dados}

O BSF ocupa uma área total de $25.404 \mathrm{~km}^{2} \mathrm{e}$ estende-se desde o trecho à jusante de Xingó em Piranhas (AL) até a foz no oceano Atlântico. A Fig. 1 apresenta a localização da área de estudo com representação de mapa hipsométrico.

Compreende as sub-bacias dos rios Ipanema, Traipu e Marituba, na margem esquerda e Capivara, Gararu e Betume na margem direita. As principais cidades são Arapiraca e Penedo em Alagoas. Suas sub-bacias hidrográficas são Alto Rio Ipanema, Baixo Ipanema/Baixo São Francisco (AL) e Baixo São Francisco em Sergipe (SE) (NEMUS, 2015). A região demonstra também uma variação na altitude, onde as áreas com as cores esverdeadas representam altitudes entre 0 e $150 \mathrm{~m}$, áreas nas cores em tons amarelo claro, escuro e alaranjadas, as altitudes são em torno de 150 a $550 \mathrm{~m}$ e, por fim, as áreas representadas nas cores com tons de rosa a vermelho, as altitudes variam de 550 a mais de $850 \mathrm{~m}$.

Os dados utilizados neste trabalho para o período de 2009 a 2018, foram obtidos através do Banco de Dados Meteorológicos para Ensino e Pesquisa (BDMEP), no site oficial do Instituto Nacional de Meteorologia (INMET), no endereço eletrônico www.inmet.gov.br, bem como no site do Sistema de Monitoramento Agrometeorológico (AGRITEMPO) da Empresa Brasileira de Pesquisa Agropecuária (EMBRAPA), no endereço eletrônico www.agri tempo.gov.br (Tabela 1).

As variáveis meteorológicas utilizadas estão descritas na Tabela 2. Ao final da tabulação dos dados, todos foram organizados em escala diária para posteriores cálculos. 


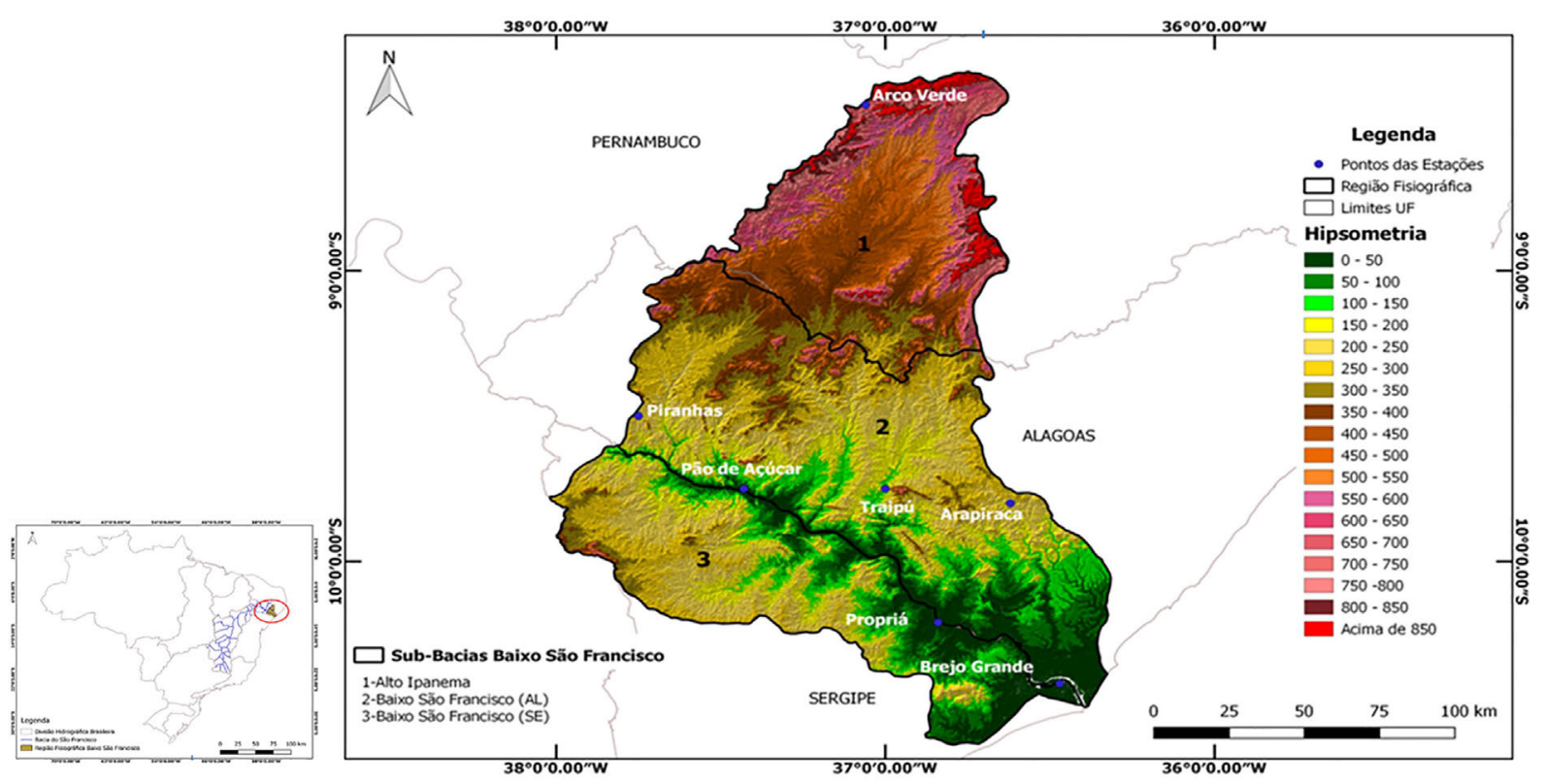

Figura 1 - Localização da área de estudo com representação de mapa hipsométrico.

Tabela 1 - Estações meteorológicas do Baixo São Francisco (A-Automática e C-Convenional).

\begin{tabular}{|c|c|c|c|c|c|c|c|}
\hline Código & Estação & UF & Latitude $\left(^{\circ}\right)$ & Longitude $\left({ }^{\circ}\right)$ & Altitude (m) & Data Fundação & Órgão \\
\hline 81953 & Arco Verde & $\mathrm{PE}$ & $-8,43$ & $-37,05$ & 684,0 & $20 / 11 / 2004$ & INMET(A) \\
\hline 81996 & Arapiraca & $\mathrm{AL}$ & $-9,80$ & $-36,61$ & 241,0 & $27 / 04 / 2008$ & INMET(A) \\
\hline 86618 & Brejo Grande & $\mathrm{SE}$ & $-10,41$ & $-36,46$ & 10,0 & $16 / 07 / 2008$ & INMET(A) \\
\hline 81994 & Pão de Açúcar & $\mathrm{AL}$ & $-9,74$ & $-37,43$ & 19,1 & $14 / 07 / 2007$ & INMET(A) \\
\hline TRMM 5650 & Piranhas & $\mathrm{AL}$ & $-9,50$ & $-37,75$ & 246,0 & $01 / 03 / 2000$ & Agritempo/EMBRAPA \\
\hline 83097 & Propriá & SE & $-10,21$ & $-36,84$ & 19,9 & $10 / 05 / 1925$ & INMET(C) \\
\hline TRMM 5507 & Traipú & $\mathrm{AL}$ & $-9,75$ & $-37,00$ & 98,0 & $01 / 03 / 2000$ & Agritempo/EMBRAPA \\
\hline
\end{tabular}

Tabela 2 - Variáveis meteorológicas utilizadas na pesquisa (AUT-Automática, CONV-Convencional e AGR-Agritempo/Embrapa).

\begin{tabular}{lcccc}
\hline \multicolumn{1}{c}{ Variável } & Unidade & Sigla & Estação & Período \\
\hline Temperatura Máxima & ${ }^{\circ} \mathrm{C}$ & Tmax & AUT/CONV/AGR & 2009 a 2018 \\
Temperatura Mínima & ${ }^{\circ} \mathrm{C}$ & $\mathrm{Tmin}$ & AUT/CONV/AGR & 2009 a 2018 \\
Temperatura do Ponto de Orvalho & ${ }^{\circ} \mathrm{C}$ & $\mathrm{Tdew}$ & AUT & 2009 a 2018 \\
Umidade Relativa & $\%$ & $\mathrm{UR}$ & AUT/CONV & 2009 a 2018 \\
Insolação & $\mathrm{Horas}$ & $\mathrm{n}$ & $\mathrm{CONVENC}$ & 2009 a 2018 \\
Radiação Solar Global & $\mathrm{MJ} \cdot \mathrm{m}^{-2} \cdot \mathrm{dia}^{-1}$ & $\mathrm{Rs}$ & AUT & 2009 a 2018 \\
Pressão Atmosférica & $\mathrm{hPa}$ & $\mathrm{P}$ & AUT & 2009 a 2018 \\
Velocidade do Vento & $\mathrm{m} \cdot \mathrm{s}^{-1}$ & $\mathrm{U}_{2}$ & AUT/CONV & 2009 a 2018 \\
Precipitação & $\mathrm{mm} \cdot \mathrm{dia}$ & Prec & AUT/CONV & 2009 a 2018 \\
\hline
\end{tabular}

\subsection{Preenchimento de falhas e teste de consistência}

No preenchimento de falhas dos dados de estações foi utilizada a técnica conhecida como MICE (Multivariate Imputation by Chained Equations) ou Imputação Multivariada por Equações Encadeadas. Esta é uma técnica de imputação múltipla que tem uma série de vantagens sobre outros métodos para tratar dados faltantes em séries temporais (Schafer e Graham, 2002). Dentro do pacote MICE, o método escolhido para imputação foi o "Predictive Mean Matching" (PMM), que é uma variante da regressão linear que determina um valor imputado calculado pelo modelo de regressão mais próximo do valor observado ( $\mathrm{Li}$ et al., 1991; Schafer, 1997). 
O PMM considera a seguinte formulação (Eq. (1)) para cada $(i)$ faltante em $(Y)$. Sendo: $(X)$ a variável sem dado faltante. Para cada $(Y)$ faltante predito, procura-se a unidade observada com valor predito mais próximo, e utiliza-se o valor observado como valor a ser imputado. A variabilidade entre imputações é gerada por meio dos passos e servem para estimar $\left(\beta^{*}\right)$ que são repetidos $\mathrm{m}$ vezes. Substituindo o valor faltante obtido pela regressão linear, tem-se:

$$
Y^{o b s}=Y_{i}^{o b s}=X_{i}^{\prime} \cdot \beta^{*}
$$

Ainda para a imputação múltipla, foi necessário utilizar como conjuntos de preditores séries da análise gradeada, com resolução espacial de $0,5^{\circ} \times 0,5^{\circ}$, do projeto Previsão dos Recursos Energéticos Mundiais (Prediction of the Worldwide Energy Resources - POWER), iniciado sob pesquisa da Administração Nacional da Aeronáutica e Espaço (National Aeronautics and Space Administration NASA).

$\mathrm{Na}$ análise da consistência dos dados resultantes da imputação foi utilizado o coeficiente de correlação de Pearson $(r)$, onde o mesmo mede a força da relação linear entre dados observados e imputados (Eq. (2)).

O coeficiente de correlação de Pearson ( $r$ ), adimensional varia entre [-1,1], sendo a pontuação perfeita igual a 1. As variáveis $(O)$ e $(P)$ são observações e imputações, respectivamente, onde $(\bar{O}) e(\bar{P})$ são médias.

$$
r=\frac{\sum_{i=1}^{n}\left(O_{i-} \bar{O}\right) *\left(P_{i}-\bar{P}\right)}{\sqrt{\sum_{i=1}^{n}\left(O_{i}-\bar{O}\right)^{2}} * \sqrt{\sum_{i=1}^{n}\left(P_{i}-\bar{P}\right)^{2}}}
$$

A interpretação detalhada do método estatístico está apresentada na Tabela 3.

$\mathrm{O}$ teste paramétrico $t$-Student, de acordo com Huang e Paes (2009), pode ser utilizado para avaliar o grau de relação entre as variáveis em questão. Na garantia de que o valor de $(r)$ refletisse a concordância entre observações e imputações, o teste $t$-Student foi utilizado com a condição de que o tamanho da amostra $(N)$, da qual se obtém o valor do coeficiente de correlação $(r)$, seja $\geq 6$. Logo, para encontrar o valor de $(t)$, utilizou-se a Eq. (3):

Tabela 3 - Coeficiente de correlação estatística ou coeficiente de correlação de Pearson.

\begin{tabular}{cc}
\hline Intervalos & Definição \\
\hline 0,00 a 0,19 & Correlação bem fraca \\
0,20 a 0,39 & Correlação fraca \\
0,40 a 0,69 & Correlação moderada \\
0,70 a 0,89 & Correlação forte \\
0,90 a 1,00 & Correlação muito forte \\
\hline
\end{tabular}

$$
t=\frac{r}{\sqrt{\left(1-r^{2}\right) /(N-2)}}
$$

A Eq. (4) é uma distribuição para $(t) \operatorname{com}(N-2)$ graus de liberdade. Uma vez obtido o valor de $(t)$, pode-se extrair o coeficiente de correlação crítico $\left(r_{c}\right)$, que é um valor para a qual se aceita ou não a hipótese estatística que existe correlação entre os dados simulados e imputados. $\mathrm{O}\left(r_{c}\right)$ é dado por:

$$
r_{c}=\sqrt{\frac{t^{2}}{(N-2)+t^{2}}}
$$

Também foi utilizado a Raiz do Erro Quadrático Médio (REQM) ou (RMSE), sigla do inglês Root Mean Square Error, definido pela Eq. (5), em que $(N)$ é o número total de elementos da amostra, $(P)=$ imputações e $(O)=$ observações em cada momento $(i)$. Interpreta-se seu valor como uma medida do desvio médio entre observado e predito, porém, deve ser observado que as diferenças entre $(O)$ e $(P)$ são elevadas ao quadrado. O coeficiente de correlação e o $(R M S E)$ foram utilizados no procedimento para validação dos cálculos de Evapotranspiração referente ao período de 2009-2018 para dados de superfície.

$$
R M S E=\sqrt{\frac{1}{N} \sum_{i=1}^{N}\left(P_{i}-O_{i}\right)^{2}}
$$

\subsection{Estimativa de dados faltosos}

O boletim $\mathrm{N}^{\circ} 56$ da FAO recomenda a metodologia desenvolvida por Allen et al. (1998), que se deve utilizar na falta de dados, quando apenas os registros de temperatura estão disponíveis. Neste trabalho os métodos foram utilizados para os municípios de Piranhas-AL e TraipúAL, utilizando dados de temperatura da estação climatológica da Agritempo/EMBRAPA.

\subsection{Estimativa da Evapotranspiração de referência (ETo)}

O método FAO Penman-Monteith é recomendado como o único método para determinar a Evapotranspiração de referência (ETo), visto que é a representação simples e próxima dos fatores fisiológicos que governam o processo de evapotranspiração.

A Eq. (6) representa o modelo padrão FAO PenmanMonteith onde, a (ETo) é a Evapotranspiração de referência $\left[\mathrm{mm} \cdot \mathrm{dia}^{-1}\right],(R n)$ é o saldo de radiação $\left[\mathrm{MJ} \cdot \mathrm{m}^{-2}\right.$. $\left.\mathrm{dia}^{-1}\right],\left(e_{s}\right)$ pressão de saturação de vapor d'água [kPa], $\left(e_{a}\right)$ pressão real de vapor $[\mathrm{kPa}],(\Delta)$ a inclinação da curva de pressão de saturação do vapor d'água em função da temperatura $\left[\mathrm{kPa} .{ }^{\circ} \mathrm{C}^{-1}\right],(\gamma)$ constante psicrométrica $[\mathrm{kPa}$. $\left.{ }^{\circ} \mathrm{C}^{-1}\right],(T)$ temperatura média diária do ar a dois metros de 
altura $\left[{ }^{\circ} \mathrm{C}\right],\left(\mathbf{u}_{2}\right)$ velocidade média do vento a dois metros de altura $\left[\mathrm{m} . \mathrm{s}^{-1}\right]$ e $(G)$ fluxo de calor no solo, onde o valor é desprezível e considerado nulo $\left[\mathrm{MJ} \cdot \mathrm{m}^{-2} \cdot \mathrm{dia}^{-1}\right]$.

$$
\text { ETo }=\frac{0,408 \Delta(R n-G)+\gamma \frac{900}{T+273} \mathbf{u}_{2}\left(e_{s}-e_{a}\right)}{\Delta+\gamma\left(1+0,34 u_{2}\right)}
$$

\subsection{Estatística descritiva dos dados de superfície}

Para a estatística descritiva foi utilizada como medida de posição a média aritmética, calculada a partir da Eq. (7) onde $(\bar{X}) \cdots$ é a média amostral e $(n)$ é o tamanho da amostra.

$$
\bar{X}=\frac{\sum_{i=1}^{n} X_{i}}{n}
$$

Quanto às formas de quantificar a variabilidade ou dispersão de um conjunto de dados, foram utilizadas as mais conhecidas: a Variância $\left(S^{2}\right)$, o Desvio Padrão $(S)$ e o Coeficiente de Variação $(\mathrm{CV})$. O $(\mathrm{CV})$ expressa em porcentagem o quanto o valor observado está distante da média. Essas medidas são definidas pelas Eqs. (8)-(10).

$$
\begin{gathered}
S^{2}=\frac{1}{n-1} \sum\left(X_{i}-\bar{X}\right)^{2} \\
S=\sqrt{S^{2}} \\
C V=S \bar{X} 100 \%
\end{gathered}
$$

\section{Resultados e Discussão}

\subsection{Análise das variáveis meteorológicas}

As estações meteorológicas escolhidas para o estudo, apresentaram dados com falhas. De acordo com a Tabela 4, as estações que tiveram maiores percentuais foram Propriá (SE) e Brejo Grande (SE), ambas do INMET, com
$41,8 \%$ e $23,7 \%$, para as variáveis velocidade do vento e radiação solar global, respectivamente.

As demais estações não ultrapassaram o percentual de $18 \%$, chegando algumas delas a ter valores mínimos de $0,2 \%$ em falhas para Tmax, Tmin e Pre, no caso das estações Piranhas (AL), Propriá (SE) e Traipú (AL) da Agritempo/EMBRAPA.

As medidas estatísticas usadas na avaliação do método de imputação foram o coeficiente de correlação $(r)$ e do REQM (Tabela 5). Os valores de $r$ e do REQM foram utilizados para as variáveis Tmax, Tmin, Tdew, UR, Rs, P, $\mathrm{U}_{2}$ e Prec, onde tiveram seus dados correspondentes a uma amostra de $\mathrm{N}=365$ dias para um ano de validação. As estações de Arco Verde (PE), Arapiraca (AL), Brejo Grande (SE) e Pão de Açúcar (AL) tiveram valores de $r$ acima de 0,90 para todas as variáveis, representando uma correlação forte entre valores observados e imputados. Uma exceção a esse resultado foi para a estação de Propriá (SE), que mostrou $r=0,62$ para a variável $\mathrm{U}_{2}$, representando uma correlação moderada.

O resultado para a velocidade média do vento mostrou uma correlação um pouco menor em relação as demais variáveis para todas as estações, não deixando de ser considerado um resultado satisfatório estatisticamente. Analisando o parâmetro REQM, ainda na (Tabela 5), a variável UR apresentou o maior erro para Pão de Açúcar e o menor erro foi para P, na localidade de Arco Verde (PE). Os valores de $r$ e do REQM das estações mostraram que o método de preenchimento é eficaz e gera valores confiáveis, levando a aceitação dos seus resultados, complementando assim as falhas nas séries.

No estudo foram observadas também, as médias dos totais mensais de precipitação para Arco Verde (PE), Arapiraca (AL), Brejo Grande (SE), Pão de Açúcar (AL), Piranhas (AL), Propriá (SE) e Traipu (AL) (Fig. 2).

Na Fig. 2, nota-se que o sinal sazonal da precipitação na região do BSF é semelhante, apresentando dois perío-

\begin{tabular}{|c|c|c|c|c|c|c|c|c|c|}
\hline Estação & $\operatorname{Tmax}\left({ }^{\circ} \mathrm{C}\right)$ & $\operatorname{Tmin}\left({ }^{\circ} \mathrm{C}\right)$ & Tdew $\left({ }^{\circ} \mathrm{C}\right)$ & UR (\%) & $\begin{array}{r}\text { N (hora) } \\
(\%) \text { de }\end{array}$ & $\begin{array}{l}\operatorname{Rs}\left(\mathrm{MJ}^{-2} \mathrm{dia}^{-1}\right) \\
\text { alhas }\end{array}$ & $\mathrm{P}(\mathrm{hPa})$ & $\mathrm{U}_{2}\left(\mathrm{~m} \cdot \mathrm{s}^{-1}\right)$ & Prec (mm.dia) \\
\hline Arco Verde (PE) & 1,6 & 1,6 & 1,7 & 1,6 & $*$ & 1,9 & 1,6 & 9,3 & 2,5 \\
\hline Arapiraca (AL) & 3,0 & 3,0 & 4,0 & 3,1 & * & 15,6 & 3,0 & 3,8 & 17,9 \\
\hline Brejo Grande (SE) (SE)(SE) & 7,3 & 7,3 & 7,3 & 18,6 & * & 23,7 & 7,3 & 7,3 & 8,1 \\
\hline Pão de Açúcar (AL) (AL) & 5,9 & 5,9 & 6,1 & 6,2 & $*$ & 6,2 & 5,8 & 7,2 & 5,9 \\
\hline Piranhas (AL) & 0,2 & 0,2 & $* *$ & $* *$ & ** & $* *$ & $* *$ & $* *$ & 0,2 \\
\hline Propriá (SE) & - & 0,2 & - & - & 0,8 & - & - & 41,8 & - \\
\hline Traipú (AL) & 0,2 & 0,2 & ** & ** & $* *$ & ** & ** & ${ }^{* *}$ & 0,2 \\
\hline
\end{tabular}
dos distintos: um chuvoso e um seco. Apesar do compor-

Tabela 4 - Percentual de falhas (\%) correspondente a um total de 3.652 dados para as variáveis de cada estação. Temperatura máxima (Tmax), Temperatura mínima (Tmin), Temperatura do ponto de orvalho (Tdew), Umidade relativa (UR), Insolação (n), Radiação solar global (Rs), Pressão atmosférica $(\mathrm{P})$, Velocidade do vento $\left(\mathrm{U}_{2}\right)$ e Precipitação (Prec). Em destaque na cor cinza, o maior percentual de falhas.

* não foi utilizada a variável para essa estação.

*** para as estações não haviam valores para essas variáveis. 
Tabela 5 - Valores de r (coeficiente de correlação) e do REQM (Raiz do erro Quadrático Médio). Valor de $r$ abaixo de 0,65 para velocidade do vento está destacado em cinza. Valores estatisticamente significativos ao nível de $5 \%$.

\begin{tabular}{|c|c|c|c|c|c|c|c|c|}
\hline \multirow[b]{2}{*}{ Estação } & \multicolumn{2}{|c|}{$\operatorname{Tmax}\left({ }^{\circ} \mathrm{C}\right)$} & \multicolumn{2}{|c|}{$\operatorname{Tmin}\left({ }^{\circ} \mathrm{C}\right)$} & \multicolumn{2}{|c|}{ Tdew $\left({ }^{\circ} \mathrm{C}\right)$} & \multicolumn{2}{|c|}{ UR (\%) } \\
\hline & $r$ & REQM & $r$ & REQM & $r$ & REQM & $r$ & REQM \\
\hline Arco Verde (PE) & 0,99 & 0,10 & 0,98 & 0,28 & 0,99 & 0,13 & 0,99 & 0,21 \\
\hline Arapiraca (AL) & 0,99 & 0,14 & 0,99 & 0,13 & 0,99 & 0,09 & 0,99 & 0,40 \\
\hline Brejo Grande (SE) & 0,98 & 0,22 & 0,98 & 0,34 & 0,99 & 0,13 & 0,96 & 1,29 \\
\hline Pão de Açúcar (AL) & 0,99 & 0,30 & 0,99 & 0,25 & 0,98 & 0,26 & 0,98 & 1,79 \\
\hline Piranhas (AL) & $*$ & * & $*$ & $*$ & $*$ & $*$ & $*$ & $*$ \\
\hline Propriá (SE) & * & * & $*$ & * & * & $*$ & $*$ & $*$ \\
\hline \multirow[t]{2}{*}{ Traipú (AL) } & $*$ & $*$ & $*$ & * & $*$ & $*$ & $*$ & $*$ \\
\hline & \multicolumn{2}{|c|}{$\operatorname{Rs}\left(\mathrm{MJ}^{-2} \mathrm{dia}^{-1}\right)$} & \multicolumn{2}{|c|}{$\mathrm{P}(\mathrm{hPa})$} & \multicolumn{2}{|c|}{$\mathrm{U}_{2}\left(\mathrm{~m} \cdot \mathrm{s}^{-1}\right)$} & \multicolumn{2}{|c|}{ Prec (mm.dia) } \\
\hline Estação & $r$ & REQM & $r$ & REQM & $r$ & REQM & $r$ & REQM \\
\hline Arco Verde (PE) & 0,98 & 0,93 & 0,99 & 0,02 & 0,91 & 0,27 & 0,99 & 0,03 \\
\hline Arapiraca (AL) & 0,97 & 1,08 & 0,99 & 0,09 & 0,97 & 0,17 & 0,97 & 1,11 \\
\hline Brejo Grande (SE) & 0,96 & 1,35 & 0,99 & 0,12 & 0,94 & 0,27 & 0,99 & 0,09 \\
\hline Pão de Açúcar (AL) & 0,99 & 0,34 & 0,99 & 0,08 & 0,93 & 0,25 & 0,98 & 0,86 \\
\hline Piranhas (AL) & $*$ & $*$ & $*$ & $*$ & $*$ & $*$ & $*$ & $*$ \\
\hline Propriá (SE) & $*$ & * & * & $*$ & 0,62 & 0,71 & * & * \\
\hline Traipú (AL) & $*$ & $*$ & * & $*$ & $*$ & $*$ & $*$ & $*$ \\
\hline
\end{tabular}

*Não houve imputação para esses dados.

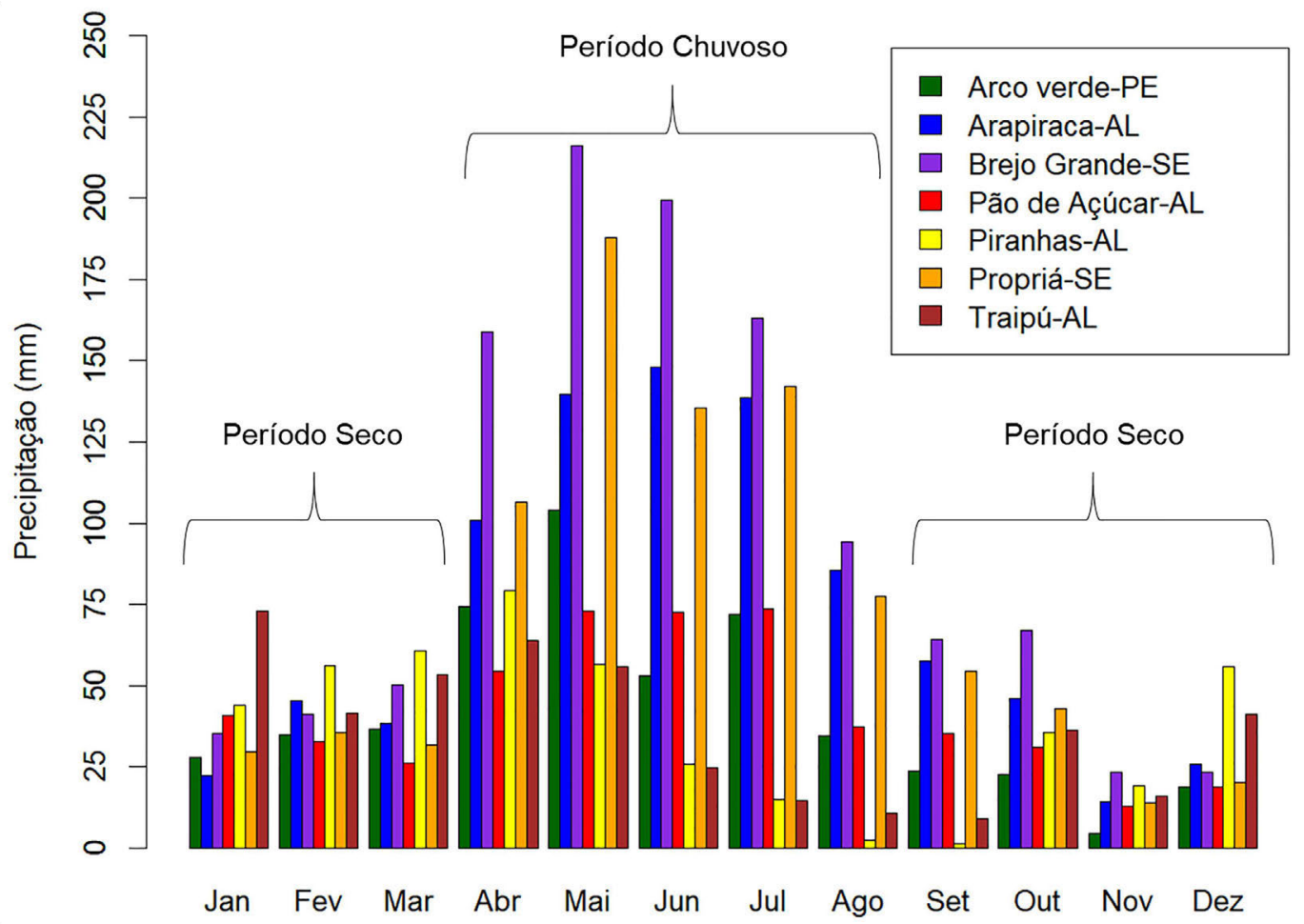

Figura 2 - Média do acumulado mensal de precipitação no Baixo para o período de 2009 a 2018.

tamento sazonal apresentar similaridade entre as localidades, as ocorrências dos máximos e dos mínimos de precipitação são relativamente diferentes. As estações de
Arco Verde, Brejo Grande e Propriá tiveram seus máximos em maio $(103,9 \mathrm{~mm}, 216,2 \mathrm{~mm}$ e 187,9 mm, respectivamente), Arapiraca teve seu máximo em junho (148,2 mm), 
Pão de Açúcar em julho (73,5 mm) e Piranhas em abril $(79,2 \mathrm{~mm})$. Sendo Traipú a única estação do BSF a apresentar seu máximo fora da quadra chuvosa, em janeiro $(72,9 \mathrm{~mm})$.

E com relação aos menores valores de precipitação, as estações de Arco Verde, Brejo Grande, Propriá, Arapiraca e Pão de Açúcar tiveram seus mínimos em novembro $(4,4 \mathrm{~mm}, 23,3 \mathrm{~mm}, 14,1 \mathrm{~mm}, 14,2 \mathrm{~mm}$ e $12,8 \mathrm{~mm}$, respectivamente), em especial, Brejo Grande que apresentou a mesma média mínima em novembro e dezembro (23,3 mm). Piranhas e Traipú apresentaram seus mínimos em setembro (1,5 $\mathrm{mm}$ e $9,0 \mathrm{~mm}$, respectivamente). $\mathrm{O}$ período chuvoso na região de estudo está compreendido entre abril a agosto. $\mathrm{O}$ período seco ocorre entre os demais meses do ano. A proximidade do litoral favorece chuvas mais abundantes, como é o caso de Brejo Grande, que teve os maiores volumes de chuva em maio. Para Santos et al. (2010), as precipitações observadas no período de maio a agosto, no Baixo São Francisco, são em geral decorrentes dos Distúrbios Ondulatórios de leste (OL), que atuam entre o Rio Grande do Norte e o norte da Bahia.

A Fig. 3 apresenta os totais anuais acumulados de precipitação para a região de estudo. Quanto ao volume de chuvas, Brejo Grande apresentou em 2009, dentre todas as estações, o maior valor $\left(1865,0 \mathrm{~mm} \cdot \mathrm{ano}^{-1}\right)$, bem como para a maioria dos anos do período, sendo a estação do BSF com o maior volume de chuvas.

No que se refere ao menor volume de chuvas, a estação de Traipú foi a que teve um menor volume no período estudado, sendo o ano de 2010 o mais chuvoso com $895,9 \mathrm{~mm} \cdot \mathrm{ano}^{-1}$. Os anos mais chuvosos do período para a BSF foram 2009 e 2010, sendo 2012 e 2018, os que apresntaram menores volumes na região. A Tabela 6 representa valores médios mensais das variáveis estudadas no período de 2009 a 2018.
Das sete localidades analisadas, as que apresentaram maiores valores de precipitação, radiação solar global, temperatura média, umidade relativa e velocidade do vento respectivamente foram: Brejo Grande $(216 \mathrm{~mm})$, Brejo Grande $\left(20,9 \mathrm{MJ} \cdot \mathrm{m}^{-2} \cdot \mathrm{dia}^{-1}\right)$, Pão de Açúcar com $\left(30,3{ }^{\circ} \mathrm{C}\right)$, Arapiraca $(69,7 \%)$ e Arco Verde $(2,4 \mathrm{~m} / \mathrm{s})$. As localidades que apresentaram os menores valores para as mesmas variáveis foram: Piranhas $(2 \mathrm{~mm})$, Arapiraca $\left(12,3 \mathrm{MJ} \cdot \mathrm{m}^{-2} \cdot \mathrm{dia}^{-1}\right)$, Arco Verde $\left(21,7{ }^{\circ} \mathrm{C}\right)$, Arco Verde $(45,6 \%)$ e Pão de Açúcar $(0,7 \mathrm{~m} / \mathrm{s})$. Com relação a temperatura média, foi observado que há um aumento da temperatura durante o período seco e uma diminuição no período chuvoso em todas as localidades, sendo este um padrão na região de estudo.

Em Pão de Açúcar verificou-se a maior amplitude térmica anual $\left(5,4{ }^{\circ} \mathrm{C}\right)$, quando comparada com as demais localidades. A menor amplitude ocorreu em Brejo Grande $\left(2,9^{\circ} \mathrm{C}\right)$, sendo esta a localidade com maiores valores de Rs e volumes de precipitação. Arco Verde foi a localidade a apresentar a menor temperatura e maior valor de velocidade de vento, resultados esses que podem estar associados a altitude $(684 \mathrm{~m})$ da localidade, entre outros aspectos. Os municípios de Piranhas e Traipú apresentaram os mesmos valores de velocidade média do vento $(2,0 \mathrm{~m} / \mathrm{s})$ durante todo o ano, pois se trata de uma média de mais de 2.000 estações meteorológicas estudadas ao redor do mundo de acordo com metodologia descrita em Allen et al. (1998).

\subsection{Análise da Evapotranspiração de referência (ETo)}

Das estações estudadas do BSF, os maiores valores diários da ETo referentes ao período de 2009 a 2018, ocorreram nos meses do período seco (janeiro, fevereiro, março, setembro, outubro, novembro e dezembro) nas estações de Arco Verde, Arapiraca, Brejo Grande e Pão de Açúcar (Fig. 4).

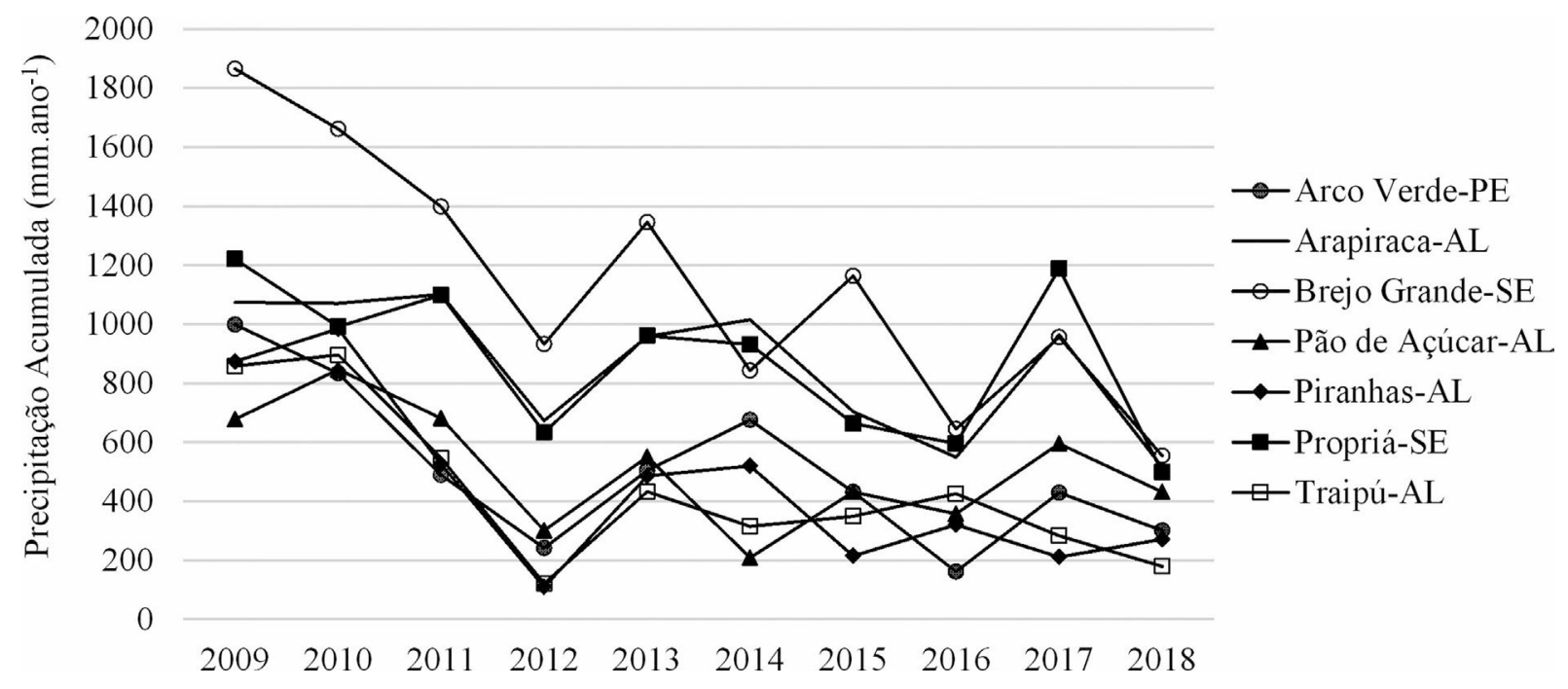

Figura 3 - Acumulado de precipitação anual $\left(\mathrm{mm} \cdot \mathrm{ano}^{-1}\right)$ para o período de 2009 a 2018 da região do BSF. 
Tabela 6 - Valores médios mensais de Prec (mm), Rs (MJ.m $\left.{ }^{-2} \cdot \operatorname{dia}^{-1}\right)$, Tmed $\left({ }^{\circ} \mathrm{C}\right), \mathrm{UR}(\%)$ e $\mathrm{U}_{2}(\mathrm{~m} / \mathrm{s})$, período de 2009 a 2018.

\begin{tabular}{|c|c|c|c|c|c|c|c|c|c|c|c|c|c|}
\hline \multirow[t]{2}{*}{ Estações } & \multirow[t]{2}{*}{ Var } & \multicolumn{12}{|c|}{ Meses } \\
\hline & & Jan & Fev & Mar & Abr & Mai & Jun & Jul & Ago & Set & Out & Nov & Dez \\
\hline \multirow[t]{5}{*}{ Arco Verde (PE) } & Prec & 28 & 35 & 37 & 75 & 104 & 53 & 72 & 34 & 24 & 23 & 4 & 19 \\
\hline & Rs & 17,4 & 15,8 & 18,6 & 16,1 & 14,1 & 12,5 & 13,4 & 15,9 & 17,8 & 18,8 & 18,3 & 17,5 \\
\hline & Tmed & 26,2 & 26,0 & 26,3 & 25,5 & 23,9 & 22,6 & 21,7 & 22,2 & 23,7 & 25,4 & 26,4 & 26,5 \\
\hline & UR & 51,4 & 49,0 & 53,7 & 56,1 & 63,3 & 62,7 & 66,1 & 61,3 & 53,9 & 51,6 & 45,6 & 48,3 \\
\hline & $\mathrm{U}_{2}$ & 2,1 & 1,9 & 1,9 & 1,9 & 2,0 & 2,0 & 2,3 & 2,3 & 2,3 & 2,4 & 2,3 & 2,2 \\
\hline \multirow[t]{5}{*}{ Arapiraca (AL) } & Prec & 22 & 45 & 38 & 101 & 140 & 148 & 139 & 85 & 58 & 46 & 14 & 26 \\
\hline & Rs & 18,7 & 16,2 & 18,5 & 15,6 & 13,8 & 12,3 & 12,5 & 14,6 & 16,2 & 18,6 & 19,5 & 19,4 \\
\hline & Tmed & 27,2 & 27,3 & 27,5 & 26,8 & 25,4 & 24,2 & 23,1 & 23,2 & 24,2 & 25,7 & 26,7 & 27,3 \\
\hline & UR & 58,1 & 54,0 & 59,0 & 60,7 & 68,2 & 67,2 & 69,7 & 67,1 & 62,1 & 60,4 & 55,4 & 56,4 \\
\hline & $\mathrm{U}_{2}$ & 1,8 & 1,5 & 1,5 & 1,2 & 1,2 & 1,1 & 1,0 & 1,2 & 1,4 & 1,8 & 2,0 & 1,9 \\
\hline \multirow[t]{5}{*}{ Brejo Grande(SE) } & Prec & 35 & 41 & 50 & 159 & 216 & 199 & 163 & 94 & 64 & 67 & 23 & 23 \\
\hline & Rs & 20,4 & 18,0 & 19,8 & 16,8 & 14,5 & 13,7 & 14,6 & 16,3 & 18,0 & 20,0 & 20,7 & 20,9 \\
\hline & Tmed & 27,7 & 27,9 & 28,0 & 27,5 & 26,6 & 25,9 & 25,2 & 25,1 & 25,5 & 26,4 & 27,1 & 27,6 \\
\hline & UR & 62,3 & 57,2 & 63,5 & 63,9 & 68,9 & 66,6 & 67,2 & 65,7 & 62,6 & 63,9 & 61,0 & 62,7 \\
\hline & $\mathrm{U}_{2}$ & 1,3 & 1,0 & 1,0 & 0,8 & 0,8 & 0,8 & 0,9 & 1,0 & 1,1 & 1,3 & 1,5 & 1,5 \\
\hline \multirow[t]{5}{*}{ Pão de Açúcar (AL) } & Prec & 41 & 33 & 26 & 54 & 73 & 73 & 74 & 37 & 35 & 31 & 13 & 19 \\
\hline & Rs & 19,9 & 17,2 & 19,8 & 16,7 & 14,5 & 13,2 & 13,5 & 16,1 & 17,5 & 19,5 & 19,8 & 19,9 \\
\hline & Tmed & 29,9 & 30,0 & 30,3 & 29,2 & 27,4 & 26,1 & 24,9 & 25,2 & 26,5 & 28,3 & 29,6 & 30,0 \\
\hline & UR & 51,2 & 47,5 & 52,2 & 55,6 & 64,0 & 63,8 & 67,4 & 63,4 & 57,4 & 54,6 & 48,3 & 49,4 \\
\hline & $\mathrm{U}_{2}$ & 1,4 & 1,2 & 1,3 & 1,0 & 0,8 & 0,7 & 0,8 & 0,9 & 1,1 & 1,3 & 1,5 & 1,4 \\
\hline \multirow[t]{5}{*}{ Piranhas (AL) } & Prec & 44 & 56 & 61 & 79 & 56 & 26 & 15 & 2 & 2 & 36 & 19 & 56 \\
\hline & Rs & 14,8 & 14,5 & 17,1 & 16,5 & 16,4 & 15,5 & 15,8 & 16,1 & 15,2 & 14,5 & 13,2 & 13,6 \\
\hline & Tmed & 28,2 & 28,4 & 28,7 & 27,4 & 25,9 & 24,6 & 23,7 & 24,1 & 25,2 & 27,0 & 28,2 & 28,3 \\
\hline & UR & 54,0 & 49,7 & 54,6 & 53,4 & 56,3 & 55,1 & 57,2 & 55,6 & 52,1 & 53,2 & 51,4 & 53,9 \\
\hline & $\mathrm{U}_{2}$ & 2,0 & 2,0 & 2,0 & 2,0 & 2,0 & 2,0 & 2,0 & 2,0 & 2,0 & 2,0 & 2,0 & 2,0 \\
\hline \multirow[t]{5}{*}{ Propriá (SE) } & Prec & 30 & 36 & 32 & 107 & 188 & 136 & 142 & 77 & 54 & 43 & 14 & 20 \\
\hline & Rs & 16,3 & 15,9 & 19,5 & 18,0 & 17,2 & 16,7 & 16,5 & 17,2 & 15,1 & 14,2 & 14,1 & 14,6 \\
\hline & Tmed & 28,4 & 28,4 & 28,9 & 28,1 & 26,6 & 25,5 & 24,5 & 24,6 & 25,4 & 27,0 & 27,9 & 28,5 \\
\hline & UR & 56,1 & 52,7 & 57,1 & 59,5 & 67,2 & 66,9 & 69,4 & 67,1 & 62,9 & 61,3 & 56,3 & 57,7 \\
\hline & $\mathrm{U}_{2}$ & 1,9 & 1,7 & 1,8 & 1,5 & 1,4 & 1,3 & 1,4 & 1,4 & 1,6 & 1,8 & 1,9 & 2,1 \\
\hline \multirow[t]{5}{*}{ Traipú (AL) } & Prec & 73 & 42 & 54 & 64 & 56 & 25 & 15 & 11 & 9 & 36 & 16 & 41 \\
\hline & Rs & 14,4 & 14,3 & 17,3 & 16,9 & 16,8 & 16,0 & 16,1 & 16,1 & 14,9 & 14,3 & 13,0 & 13,4 \\
\hline & Tmed & 28,0 & 28,2 & 28,6 & 27,4 & 25,8 & 24,6 & 23,7 & 23,9 & 24,8 & 26,4 & 27,6 & 28,0 \\
\hline & UR & 54,7 & 50,3 & 54,2 & 52,7 & 55,6 & 54,2 & 56,7 & 55,6 & 52,7 & 53,7 & 51,8 & 54,2 \\
\hline & $\mathrm{U}_{2}$ & 2,0 & 2,0 & 2,0 & 2,0 & 2,0 & 2,0 & 2,0 & 2,0 & 2,0 & 2,0 & 2,0 & 2,0 \\
\hline
\end{tabular}

Já para as estações de Piranhas, Propriá e Traipú, ambas tiveram seus menores valores tanto no período chuvoso (abril, maio, julho e julho) como no período seco (setembro, outubro, novembro e dezembro), o que demonstrou ciclos anuais diferentes para essas localidades.

A ETo apresentou seus menores valores médios diários para as estações meteorológicas das cidades de Arco Verde $\left(3,3 \mathrm{~mm} \mathrm{dia}{ }^{-1}\right)$, Arapiraca $\left(3,0 \mathrm{~mm} \mathrm{dia}{ }^{-1}\right)$, Brejo Grande $\left(3,6 \mathrm{~mm} \cdot \mathrm{dia}^{-1}\right)$, Pão de Açúcar $\left(3,4 \mathrm{~mm} \cdot \mathrm{dia}^{-1}\right)$ e Propriá $\left(3,9 \mathrm{~mm} \cdot \mathrm{dia}^{-1}\right)$, nos meses de junho (Arco Verde e
Brejo Grande) e em julho (Arapiraca, Pão de Açúcar e Propriá). Esse resultado, também diferiu das cidades de Piranhas (4,2 mm.dia $\left.{ }^{-1}\right)$ em dezembro, e Traipú (4,1 mm. $\left.\mathrm{dia}^{-1}\right)$ em novembro.

Com relação aos maiores valores médios diários de ETo, ocorreram no mês de novembro para Arco Verde (5,8 mm.dia $\left.{ }^{-1}\right)$ e Arapiraca $\left(5,0 \mathrm{~mm} \cdot \mathrm{dia}^{-1}\right)$, em março para Brejo Grande $\left(5,0 \mathrm{~mm} \cdot \mathrm{dia}^{-1}\right)$, Pão de Açúcar $\left(5,7 \mathrm{~mm} \cdot \mathrm{dia}^{-1}\right)$, Piranhas $\left(5,1 \mathrm{~mm} \cdot \mathrm{dia}^{-1}\right)$, Propriá $\left(5,5 \mathrm{~mm} \cdot \mathrm{dia}^{-1}\right)$ e Traipú $\left(5,2 \mathrm{~mm} \cdot \mathrm{dia}^{-1}\right)$. 


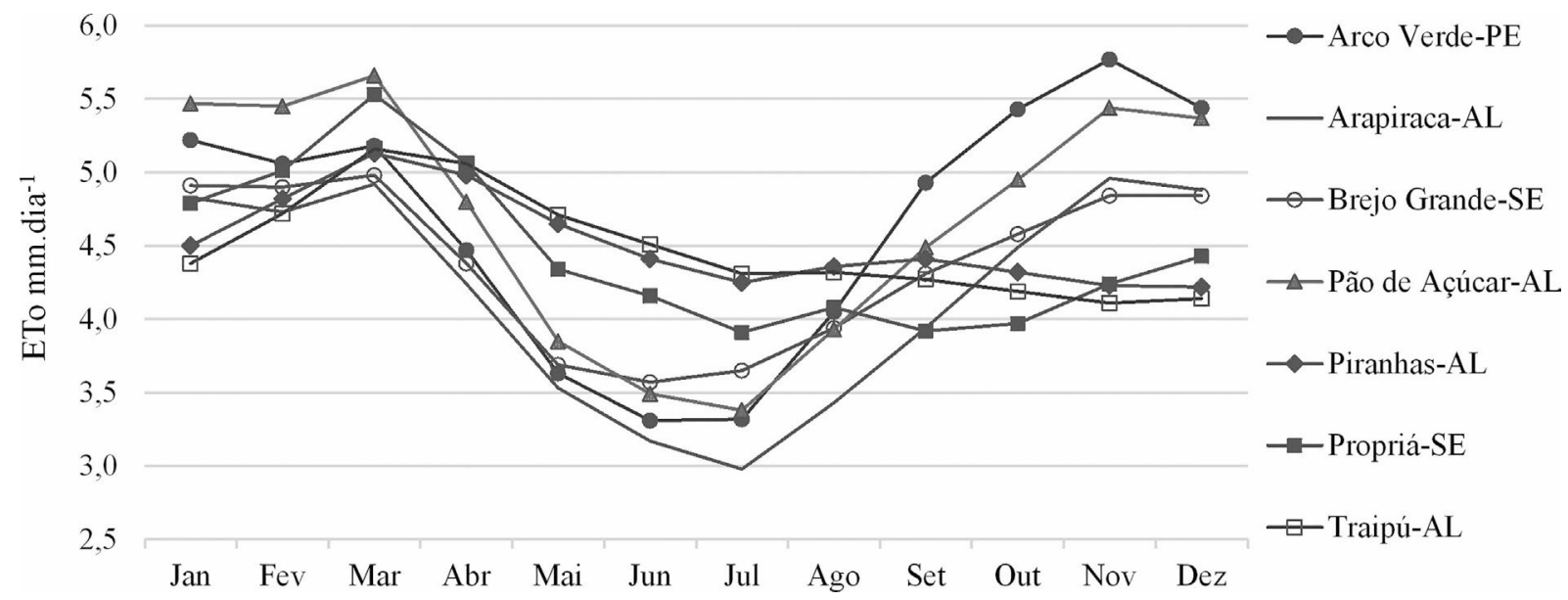

Figura 4 - Média diária da Evapotranspiração de referência (ETo) no período de 2009 a 2018.

A baixa (ETo) observada durante o período chuvoso (abril a julho) está associada às temperaturas mais baixas e ao ar mais úmido no inverno (Tabela 6). Em estudos de Barros et al. (2017), a Evapotranspiração de referência no perímetro irrigado Jacaré-Curituba, na cidade de CanindéSE, segundo dados do modelo de Penman-Monteith $(\mathrm{PM})$, atingiu uma média diária de (ETo) de $5,81 \mathrm{~mm}$. $\mathrm{dia}^{-1}$. Este estudo foi um dos poucos encontrados para a região do Baixo São Francisco durante a realização desta pesquisa.

Quanto à dispersão dos dados observados por meio do Coeficiente de Variação (CV), nota-se que Arco Verde
(PE) apresentou maior variabilidade quando comparada às demais estações, nos meses do período chuvoso $(\sim 12,2 \%)$. Para uma média anual, Piranhas (AL) e Traipú (AL) apresentaram menores dispersões $(\sim 4,8 \%$ e 5,38$)$ respectivamente (Tabela 7).

Tiveram maiores dispersões as localidades de Arco Verde (PE) $(\sim 10,7 \%)$, Brejo Grande (SE) $(\sim 10,1 \%)$, Propriá (SE) $(\sim 9,4 \%)$ e Arapiraca (AL) $(\sim 9,0 \%)$. Pode-se considerar então, que de um modo geral a ETo na região de estudo apresenta dispersão dos dados de moderada a baixa com relação à média, também demonstrando ser a média um bom indicador para representar a mesma.

Tabela 7 - Estatística descritiva dos valores médios mensais de Evapotranspiração de referência (ETo), para o período de 2009 a 2018. Estações de Arco Verde (PE), Arapiraca (AL), Brejo Grande (SE) e Pão de Açúcar (AL) (a). Estações de Piranhas (AL), Propriá (SE) e Traipú (AL) (b).

\begin{tabular}{|c|c|c|c|c|c|c|c|c|c|c|c|c|}
\hline \multirow[t]{2}{*}{ Mês } & \multicolumn{3}{|c|}{ Arco Verde (PE) } & \multicolumn{3}{|c|}{ Arapiraca (AL) } & \multicolumn{3}{|c|}{ Brejo Grande (SE) } & \multicolumn{3}{|c|}{ Pão de Açúcar (AL) } \\
\hline & $\begin{array}{c}\text { Média }(\mathrm{mm} . \\
\left.\mathrm{dia}^{-1}\right)\end{array}$ & $\begin{array}{c}\mathrm{DP} \\
(\mathrm{mm}) \\
\end{array}$ & $\begin{array}{l}\mathrm{CV} \\
(\%) \\
\end{array}$ & $\begin{array}{c}\text { Média (mm. } \\
\left.\mathrm{dia}^{-1}\right)\end{array}$ & $\begin{array}{c}\mathrm{DP} \\
(\mathrm{mm}) \\
\end{array}$ & $\begin{array}{l}\mathrm{CV} \\
(\%) \\
\end{array}$ & $\begin{array}{c}\text { Média (mm. } \\
\left.\mathrm{dia}^{-1}\right)\end{array}$ & $\begin{array}{c}\mathrm{DP} \\
(\mathrm{mm})\end{array}$ & $\begin{array}{l}\mathrm{CV} \\
(\%) \\
\end{array}$ & $\begin{array}{c}\text { Média (mm. } \\
\left.\mathrm{dia}^{-1}\right)\end{array}$ & $\begin{array}{c}\mathrm{DP} \\
(\mathrm{mm})\end{array}$ & $\begin{array}{l}\mathrm{CV} \\
(\%) \\
\end{array}$ \\
\hline Jan & 5,22 & 0,59 & 11,3 & 4,83 & 0,29 & 6,0 & 4,91 & 0,42 & 8,4 & 5,47 & 0,58 & 10,5 \\
\hline Fev & 5,06 & 0,68 & 13,4 & 4,73 & 0,23 & 4,9 & 4,90 & 0,39 & 8,0 & 5,45 & 0,38 & 7,0 \\
\hline Mar & 5,18 & 0,41 & 7,9 & 4,92 & 0,26 & 5,2 & 4,98 & 0,34 & 6,8 & 5,66 & 0,41 & 7,2 \\
\hline Abr & 4,47 & 0,48 & 10,8 & 4,24 & 0,52 & 12,3 & 4,38 & 0,44 & 10,0 & 4,80 & 0,43 & 9,0 \\
\hline Mai & 3,63 & 0,54 & 14,8 & 3,53 & 0,53 & 14,8 & 3,69 & 0,56 & 15,0 & 3,85 & 0,47 & 12,3 \\
\hline Jun & 3,31 & 0,33 & 10,0 & 3,17 & 0,24 & 7,6 & 3,57 & 0,48 & 13,3 & 3,49 & 0,27 & 7,6 \\
\hline Jul & 3,32 & 0,45 & 13,5 & 2,98 & 0,18 & 5,9 & 3,65 & 0,56 & 15,4 & 3,38 & 0,28 & 8,2 \\
\hline Ago & 4,05 & 0,46 & 11,4 & 3,43 & 0,33 & 9,5 & 3,94 & 0,49 & 12,3 & 3,93 & 0,35 & 8,9 \\
\hline Set & 4,93 & 0,44 & 8,9 & 3,94 & 0,47 & 11,8 & 4,31 & 0,40 & 9,3 & 4,49 & 0,45 & 10,0 \\
\hline Out & 5,43 & 0,47 & 8,6 & 4,49 & 0,63 & 13,9 & 4,58 & 0,37 & 8,1 & 4,95 & 0,38 & 7,6 \\
\hline Nov & 5,77 & 0,61 & 10,6 & 4,96 & 0,53 & 10,7 & 4,84 & 0,38 & 7,9 & 5,44 & 0,34 & 6,2 \\
\hline Dez & 5,44 & 0,40 & 7,4 & 4,88 & 0,27 & 5,5 & 4,84 & 0,33 & 6,7 & 5,37 & 0,27 & 4,9 \\
\hline Méd & 4,65 & & & 4,18 & & & 4,80 & & & 4,69 & & \\
\hline \multicolumn{2}{|c|}{$\begin{array}{l}\text { Total Anual ETo } \\
\text { (mm) }\end{array}$} & \multicolumn{2}{|c|}{1697,38} & & \multicolumn{2}{|c|}{1523,61} & & \multicolumn{2}{|c|}{1599,46} & & \multicolumn{2}{|c|}{1711,28} \\
\hline
\end{tabular}


(b)

\begin{tabular}{|c|c|c|c|c|c|c|c|c|c|}
\hline \multirow[t]{2}{*}{ Mês } & \multicolumn{3}{|c|}{ Piranhas (AL) } & \multicolumn{3}{|c|}{ Propriá (SE) } & \multicolumn{3}{|c|}{ Traipú (AL) } \\
\hline & Média $\left(\mathrm{mm} \cdot \mathrm{dia}^{-1}\right)$ & D.P (mm) & CV $(\%)$ & Média $\left(\mathrm{mm} \cdot \mathrm{dia}^{-1}\right)$ & $\mathrm{DP}(\mathrm{mm})$ & C.V (\%) & Média $\left(\mathrm{mm} \cdot \mathrm{dia}^{-1}\right)$ & $\mathrm{DP}(\mathrm{mm})$ & C.V $(\%)$ \\
\hline Jan & 4,50 & 0,16 & 3,6 & 4,79 & 0,35 & 7,3 & 4,38 & 0,16 & 3,7 \\
\hline Fev & 4,82 & 0,18 & 3,7 & 5,01 & 0,32 & 6,3 & 4,72 & 0,22 & 4,6 \\
\hline Mar & 5,13 & 0,17 & 3,4 & 5,53 & 0,36 & 6,4 & 5,16 & 0,20 & 3,8 \\
\hline Abr & 4,98 & 0,25 & 5,1 & 5,06 & 0,45 & 8,9 & 5,06 & 0,35 & 6,9 \\
\hline Mai & 4,65 & 0,33 & 7,0 & 4,34 & 0,52 & 11,9 & 4,71 & 0,31 & 6,5 \\
\hline Jun & 4,41 & 0,20 & 4,5 & 4,16 & 0,30 & 7,1 & 4,51 & 0,27 & 5,9 \\
\hline Jul & 4,25 & 0,23 & 5,3 & 3,91 & 0,27 & 6,8 & 4,31 & 0,30 & 6,8 \\
\hline Ago & 4,36 & 0,20 & 4,6 & 4,08 & 0,43 & 10,4 & 4,32 & 0,27 & 6,3 \\
\hline Set & 4,41 & 0,31 & 6,9 & 3,92 & 0,48 & 12,2 & 4,27 & 0,29 & 6,7 \\
\hline Out & 4,32 & 0,19 & 4,4 & 3,97 & 0,63 & 15,9 & 4,19 & 0,23 & 5,5 \\
\hline Nov & 4,23 & 0,24 & 5,6 & 4,24 & 0,55 & 12,9 & 4,11 & 0,19 & 4,7 \\
\hline Dez & 4,22 & 0,15 & 3,5 & 4,43 & 0,32 & 7,3 & 4,14 & 0,13 & 3,2 \\
\hline Méd & 4,52 & & & 4,45 & & & 4,49 & & \\
\hline \multicolumn{2}{|c|}{ Total Anual ETo (mm) } & \multicolumn{2}{|c|}{1650,42} & & \multicolumn{2}{|c|}{1625,54} & & \multicolumn{2}{|c|}{1638,93} \\
\hline
\end{tabular}

*Desvio Padrão (DP) e Coeficiente de Variação (CV).

A Fig. 5 apresenta valores totais anuais médios de ETo (mm.mês ${ }^{-1}$ ) ao longo do período de estudo, bem como a média do período de 2009 a 2018 (linha vermelha tracejada) e a média simples anual (círculo fechado em vermelho).

Para Arco Verde, localidade representante da Subbacia do Alto Ipanema, apresentou seu maior e menor valor médio observado de 154,1 mm.mês ${ }^{-1}$ em 2012 e
130,9 mm.mês ${ }^{-1}$ em 2014, tendo sua média dos dez anos um valor de 141,4 mm.mês ${ }^{-1}$. Para esta localidade, os anos de maiores demandas hídricas foram 2012, 2015 e 2016, ambos acima da média do período, estando os demais anos abaixo da média.

Quanto a dispersão dos dados, os anos de 2009 e 2017 apresentaram maiores variabilidades, sendo os anos de 2010 e 2018 os que tiveram a média simples e sua me-

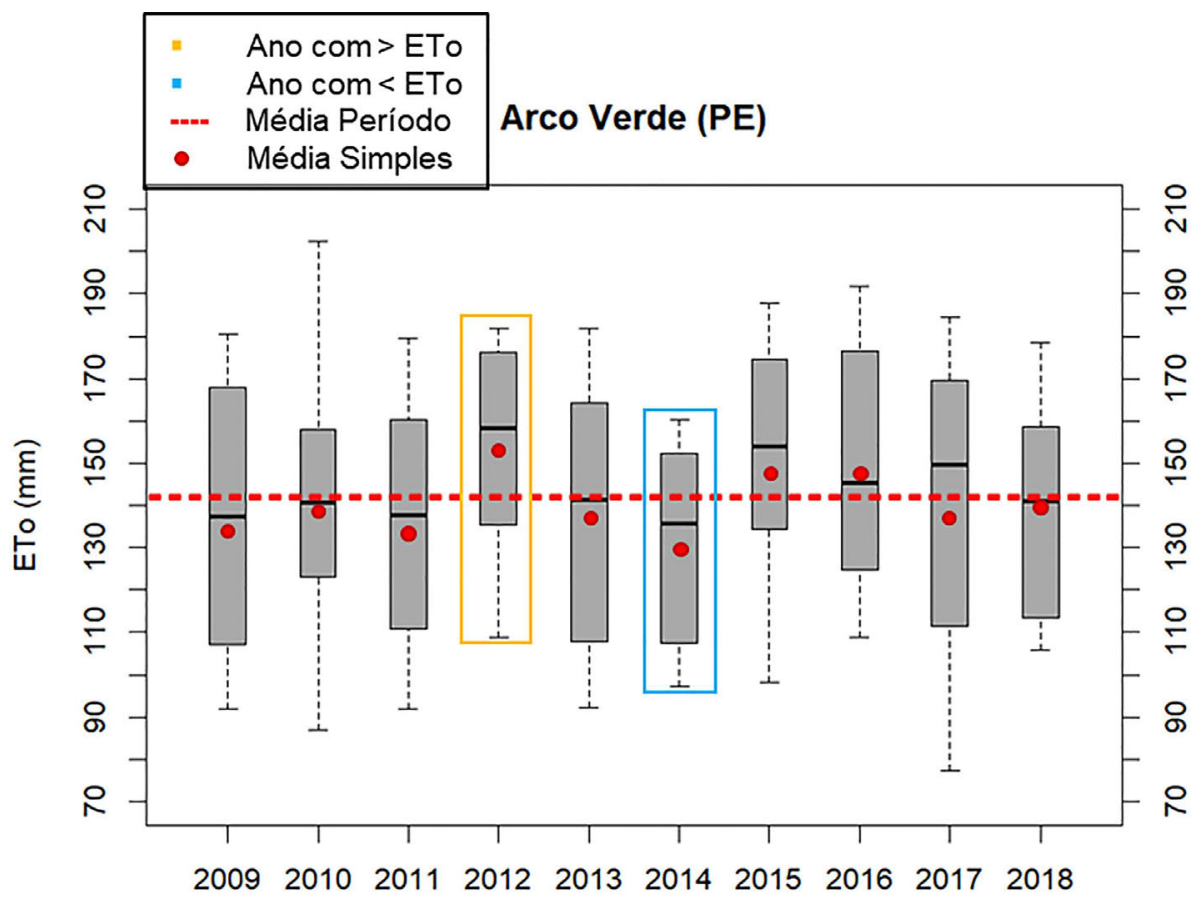

Figura 5 - Boxplot da variação do total médio anual da Evapotranspiração de referência (ETo) $\left(\mathrm{mm} . \mathrm{mês}^{-1}\right)$, observada na estação meteorológica de Arco Verde (Sub-bacia do Alto Ipanema) para o período de 2009 a 2018. Destaque em amarelo (ano com maior ETo) e destaque em azul (ano com menor ETo). 
diana mais próxima da média do período, o que significa que de todos os anos, estes apresentaram pouca variabilidade em $50 \%$ do seu conjunto de dados em ralação a média.

Na Fig. 6 estão representadas as médias do período de estudo para as localidades pertencentes a Sub-bacia do Baixo São Francisco (AL).

As médias encontradas foram: Arapiraca $(126,9 \mathrm{~mm}$. mês $\left.{ }^{-1}\right)$, Pão de Açúcar $\left(142,6 \mathrm{~mm} \cdot \mathrm{mês}^{-1}\right)$, Piranhas (137,5 mm.mês $\left.{ }^{-1}\right)$ e Traipú (136,5 mm.mês $\left.{ }^{-1}\right)$. Os anos que apresentaram maiores valores dos totais anuais médios de evaporação na região foram em 2015 para Pão de Açúcar (154,0 mm.mês $\left.{ }^{-1}\right)$, Piranhas (144,6 mm mês $\left.{ }^{-1}\right)$ e Traipú $\left(147,73 \mathrm{~mm} \cdot \mathrm{mês}^{-1}\right)$ e, no ano de 2016 para Arapiraca $\left(138,5 \mathrm{~mm} \cdot \mathrm{mês}^{-1}\right)$. Os menores valores foram nos anos de 2011 para Arapiraca $\left(118,1 \mathrm{~mm} . \mathrm{mês}^{-1}\right)$, Traipú $\left(131,0 \mathrm{~mm} \cdot \mathrm{mês}^{-1}\right)$ e Pão de Açúcar $\left(131,5 \mathrm{~mm} \cdot \mathrm{mês}^{-1}\right)$ e, no ano de 2012 para Piranhas (134,4 mm.mês $\left.{ }^{-1}\right)$.
Para a região, a maior demanda hídrica ocorreu no município de Pão de Açúcar em 2015 e a menor em Arapiraca em 2011. Ainda na Fig. 6, uma análise sobre a dispersão dos dados na região mostra que Pão de Açúcar apresentou em 2017 uma maior variabilidade nos valores de evapotranspiração e Piranhas teve em 2018, uma menor variabilidade.

Para a Sub-bacia do Baixo São Francisco (SE) (Fig. 7), as localidades de Brejo Grande e Propriá, apresentaram como médias para o período 133,2 e 135,4 mm. mês ${ }^{-1}$, respectivamente.

Também apresentaram como maiores e menores totais anuais médios no ano de 2018 e $2010(152,8$ e 122,4 mm.mês ${ }^{-1}$ ) em Brejo Grande e 2015 e 2014 (146,0 e 124,7 mm.mês $\left.{ }^{-1}\right)$ em Propriá, respectivamente. A maior e menor demanda hídrica ocorreu em 2018 e 2010, respectivamente, na localidade de Brejo Grande, bem como foi a localidade nessa sub-bacia que apresentou em

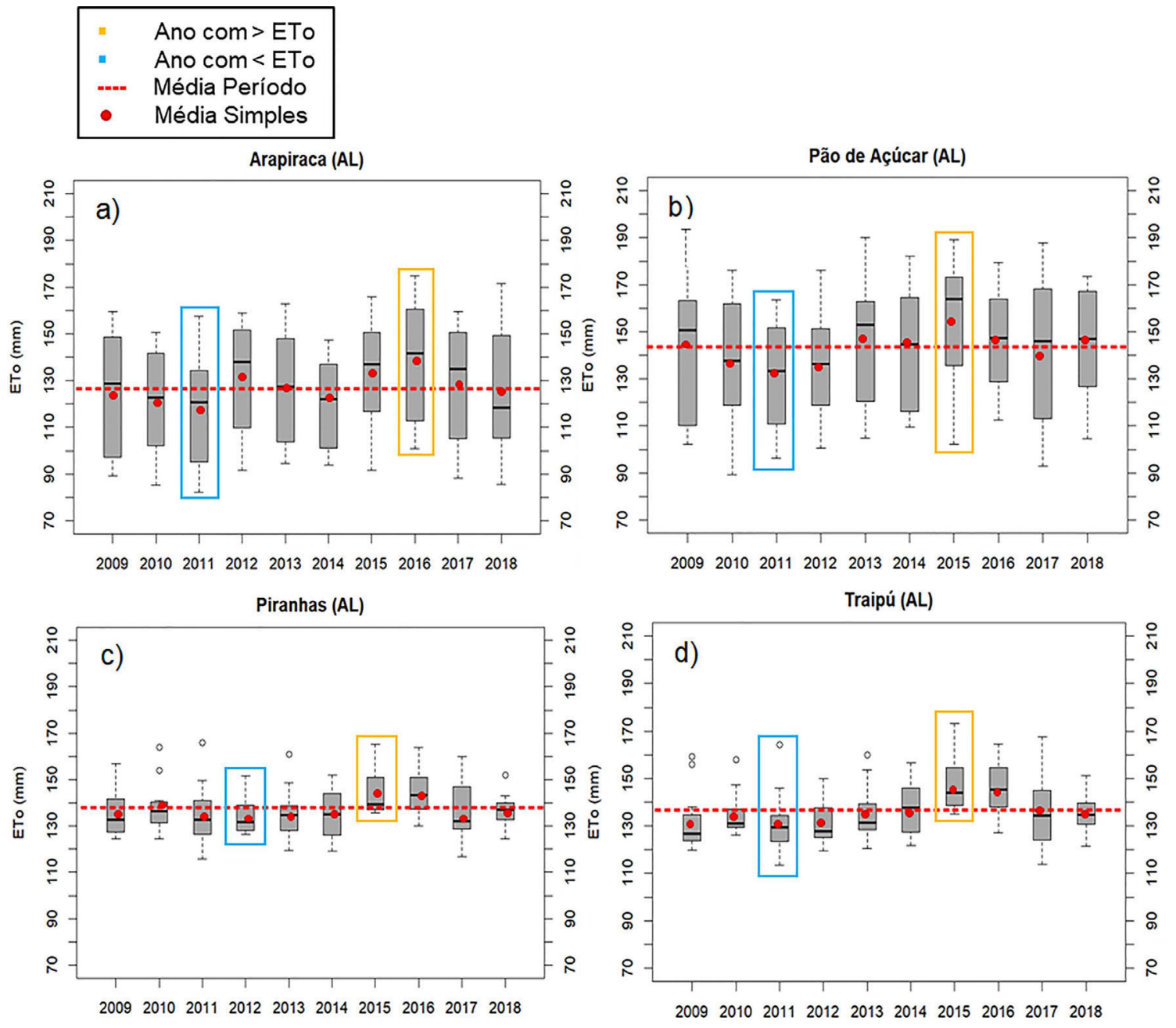

Figura 6 - Boxplot da variação do total médio anual da Evapotranspiração de referência (ETo) (mm.mês ${ }^{-1}$ ) observada nas estações meteorológicas dos municípios de Arapiraca (a), Pão de Açúcar (b), Piranhas (c) e Traipú (d), representantes da Sub-bacia do Baixo São Francisco (AL), para o período de 2009 a 2018. Destaque em amarelo (ano com maior ETo) e destaque em azul (ano com menor ETo). 


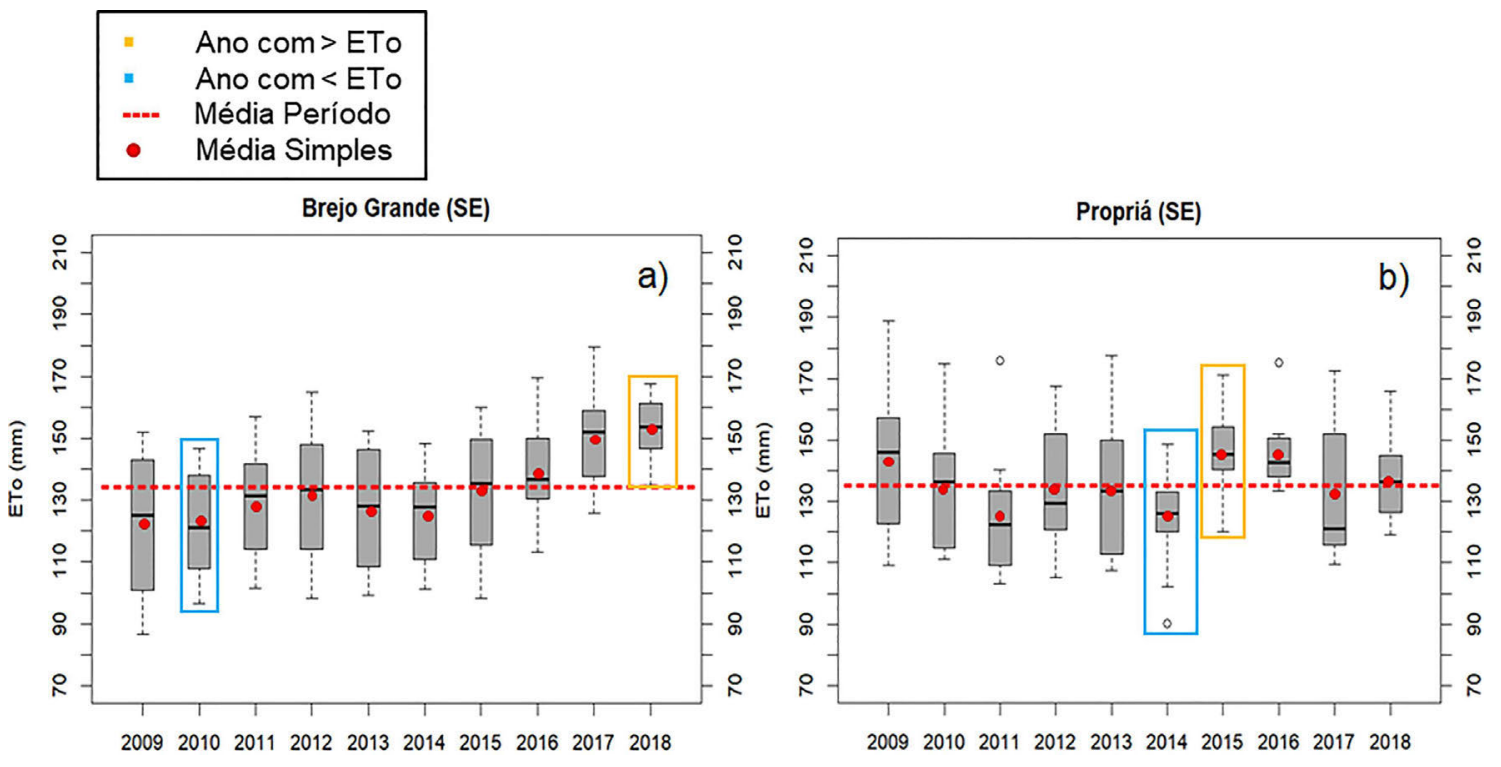

Figura 7 - Boxplot da variação do total médio anual da Evapotranspiração de referência (ETo) (mm.mês ${ }^{-1}$ ) observada nas estações meteorológicas dos municípios de Brejo grande (a) e Propriá (b), representantes da Sub-bacia do Baixo São Francisco (SE), para o período de 2009 a 2018 . Destaque em amarelo (ano com maior ETo) e destaque em azul (ano com menor ETo).

2009, maior variabilidade, tendo Propriá apresentado, a menor variabilidade em 2014.

Uma observação importante a se fazer com relação a este resultado é de que Brejo Grande apresentou de 2009 a 2015 valores médios mensais de ETo abaixo da média do período. Resultado esse que variou durante os dez anos de estudo para a localidade de Propriá. As duas estações da sub-bacia do BSF (SE) demonstraram um comportamento diferenciado em relação as demais localidades. Esses resultados corroboram com valores médios de umidade relativa do ar para estas estações (Tabela 6).

\section{Conclusões}

O BSF ainda é uma das regiões fisiográficas da Bacia Hidrográfica do São Francisco menos estudada, no que se refere aos processos físicos atmosféricos inerentes à evapotranspiração. Os resultados deste trabalho permitiram concluir que as médias diárias anuais da ETo, no período de 2009 a 2018, para as estações estudadas, foram: Arco Verde $(4,6)$, Arapiraca $(4,18)$, Brejo Grande $(4,80)$, Pão de Açúcar $(4,69)$, Piranhas (4,52), Propriá $(4,45)$ e Traipú $(4,49) \mathrm{mm}_{\mathrm{dia}}{ }^{-1}$.

É importante frisar que a estação de Pão de Açúcar (AL) teve a maior média anual acumulada de ETo da série de dez anos, correspondendo à $1711,28 \mathrm{~mm}_{\text {.ano }}^{-1}$ e a estação de Arapiraca (AL) aparece com a menor média acumulada do Baixo São Francisco com o valor de 1523,61 mm.ano ${ }^{-1}$. A média do total anual acumulada de (ETo) do BSF para o período de estudo foi de $1635,23 \mathrm{~mm} \cdot \mathrm{ano}^{-1}$. Esse resultado foi semelhante aos estudos de Silva (2017), que tiveram média anual de ETo para o Baixo São Francisco o valor de 1631,94 mm.ano ${ }^{-1}$.

As estimativas de ETo pelo método PM-FAO, proporcionaram uma análise da dinâmica da ETo na região, que foram significativas para a identificação de padrões ocorridas no Baixo São Francisco.

\section{Agradecimentos}

Os autores agradecem a Coordenação de Aperfeiçoamento de Pessoal de Nível Superior (CAPES) pelo apoio financeiro concedido durante a concepção deste estudo. O primeiro autor agradece especialmente ao $\mathrm{CNPq}$ pela concessão de sua bolsa de mestrado junto ao Programa de Pós Graduação em Meteorologia (PPGMET) do ICAT/ UFAL.

\section{Referências}

ALLEN, R.G.; SMITH, M.; PERRIER, A. An update for the definition of reference evapotranspiration. ICID Bulletin, v. 43, n. 2, p.1-34, 1994.

ALLEN-RICHARD, G.; PEREIRA-LUIS, S.; DIRK, R.; MARTIN, S. FAO irrigation and drainage paper No. 56. Rome. Journal of Food and Agriculture Organization of the United Nations, v. 56, n.5-6, p. 97-156, 1998.

AGÊNCIA NACIONAL DE ÁGUAS. Conjuntura dos Recursos Hídricos no Brasil: Regiões Hidrográficas brasileiras - Edição Especial. Brasília: ANA, 2015.

BARROS, A.; AGUIAR NETTO, A.O.; MEDEIROS, P.R.F.; SILVA, T.M.M.; ALBUQUERQUE, K.A.D. Comparação entre métodos de estimativa da evapotranspiração de referência em perímetro irrigado no Baixo São Francisco. 
Revista Brasileira de Agricultura Irrigada, v. 11, n. 8, p. 2183-2193, 2017.

CABRAL J.J.B.; ALMEIDA, H.A.; SILVA, C.M.S. Comparação de Dados Diários de Evapotranspiração de Referência Estimados pelos Métodos de Penman-Monteith e Tanque Classe A, para Campina Grande, PB. Trabalho de Conclusão de Curso de Especialização Latu Sensu, Universidade Estadual da Paraíba, 2014.

CAMARGO, A.P.; SENTELHAS, P.C. Avaliação do desempenho de diferentes métodos de estimativa da evapotranspiração potencial no estado de São Paulo. Revista Brasileira de Agrometeorologia, v. 5, n. 1, p. 89-97, 1997.

CHIN, D.A.; ZHAO, S. Evaluation of evaporation-pan networks. Journal of Irrigation and Drainage Engineering, v. 121, n. 5, p. 338-346, 1995.

FERNANDES, R.; KOROLEVYCH, V.; WANG, S. Trends in land evapotranspiration over Canada for the period 19602000 based on in situ climate observations and a land surface model. Journal of Hidrometeorology, v. 8, n. 5, p. 1016-1030, 2007.

JENSEN, M.E.; BURMAN, R.D.; ALLEN, R.G. Evapotranspiration and Irrigation Water Requirements. New York: American Society of Civil Engineers, 360 p, 1990.

HUANG, G.; PAES, A.T. Posso usar o teste t de Student quando preciso comparar três ou mais grupos? Einsten: Educação Continuada em Saúde, v. 7 n. 2, p. 63-64, 2009.

LIANG, L.; LI, L.; LIU, Q. Temporal variation of reference evapotranspiration during 1961-2005 in the Taoer River basin of Northeast China. Agricultural and Forest Meteorology, v. 150, n. 2, p. 298-306, 2009.

LI, K.H.; RAGHUNATHAN, T.E.; RUBIN, D.B. Large-sample significance levels from multiply imputed data using moment-based statistics and an $\mathrm{f}$ reference distribution. Journal of the American Statistical Association, v. 86, n. 486, p. 1065-1073, 1991.

MARENGO, J. A. Vulnerabilidade, impactos e adaptação à mudança do clima no semi-árido do Brasil. Parcerias Estratégicas, v. 13, n. 27, p. 149-176, 2008.

MARENGO, J.A.; CUNHA, A.P.; ALVES, L.M. A seca de 2012-15 no semiárido do Nordeste do Brasil no contexto histórico. Climanalise, v. 3, n. esp., p. 1-6, 2016.

MEDEIROS, A.T. Estimativa da Evapotranspiração de Referência a Partir da Equação de Penman-Monteith, de Medidas Lisimétricas e de Equações Empíricas, em Paraipaba, CE. Tese de Doutorado em Agronomia, Escola Superior de Agricultura "Luiz de Queiroz", Universidade de São Paulo. Piracicaba, SP, 103 p., 2002.

NEMUS GESTÃO E REQUALIFICAÇÃO AMBIENTAL LTDA. Plano de Recursos Hídricos da Bacia Hidro- gráfica do Rio São Francisco. RP1A - Diagnóstico da Dimensão Técnica e Institucional. Volume 1 - Caracterização da Bacia Hidrográfica - $\mathbf{1}^{\text {a }}$ Parte. Salvador: Nemus, 2015.

PEREIRA, A.R. Introdução à Micrometeorologia. Piracicaba: ESALQ, 70 p., 1998.

SANTIAGO, A.V. Evapotranspiração de Referência Medida por Lisímetro de Pesagem e Estimada por PenmanMonteith (FAO-56), nas Escalas Mensal e Decendial. Dissertação de Mestrado em Agronomia, Escola Superior de Agricultura Luiz de Queiroz, Piracicaba, 37 p., 2001.

SCHAFER, J.L. Analysis of Incomplete Multivariate Data. London: Chapman and Hall/CRC, 444 p., 1997.

SCHAFER, J.L.; Graham, J.W. Missing data: our view of the state of the art. Psychological Methods, v. 7, n. 2, p. 147177, 2002.

SEDIYAMA, G.C. Estimativa da evapotranspiração: histórico, evolução e análise crítica. Revista Brasileira de Agrometeorologia, v. 4, n. 1, p. 1-7, 1996.

SILVA, S.S. Comparação de Métodos Empírico-Teóricos de Estimativa de Evapotranspiração de Referência ao Modelo de Penman-Monteith. Dissertação de Mestrado, Universidade Federal de Goiás, Goiânia, 2017.

SILVA, N.D. Estimativa, Análise Espacial e Temporal da Evapotranspiração de Referência (ETo) na Bacia Hidrográfica do Rio São Francisco, Brasil. Dissertação de Mestrado, Universidade Federal do Recôncavo da Bahia, Cruz das Almas, 2017.

SILVA, H.J.F. Análise de Tendência e Caracterização Sazonal e Interanual da Evapotranspiração e Referência para o Sudoeste da Amazônia Brasileira; Acre, Brasil. Dissertação de Mestrado, UFRN, Natal, 2015.

SMITH, M. Report on Expert Consultation on Procedures for Revision of FAO Methodologies for Crop Water Requirements. Rome: FAO, 45 p., 1991.

SMITH, M. The application of climatic data for planning and management of sustainable rainfed and irrigated crop production. Agricultural and Forest Meteorology, v. 103, n. 1, p. 99-108, 2000.

\section{Endereços de Internet}

AGRITEMPO. Endereço eletrônico: www.agritempo.gov.br INMET. Endereço eletrônico: www.inmet.gov.br

License information: This is an open-access article distributed under the terms of the Creative Commons Attribution License (type CC-BY), which permits unrestricted use, distribution and reproduction in any medium, provided the original article is properly cited. 